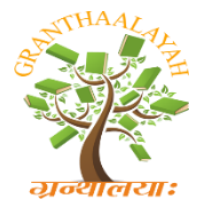

\author{
INTERNATIONAL JOURNAL OF RESEARCH - \\ GRANTHAALAYAH \\ A knowledge Repository
}

Science

\title{
DIETARY INTAKE AND PREVALENCE OF ADOLESCENT HYPERTENSIVE IN PORT HARCOURT, NIGERIA
}

\author{
Wordu G. O. ${ }^{1}$, Wachukwu- Chikodi H. I. ${ }^{1}$ \\ ${ }^{1}$ Department of Food Science and Technology, Rivers State University, Nkpolu - Port Harcourt
}

\begin{abstract}
Hypertension is the commonest non communicable disease affecting both adolescents and adults. Its origin is in childhood, but information on its prevalence and associated risk factors in adolescents are scarce. This study assessed the prevalence of High blood pressure and associated risk factors on an adolescents in Port Harcourt, Nigeria. A cross-sectional descriptive study of 150 respondents selected using a multistage sampling technique from secondary schools in Port Harcourt. Height, weight and blood pressure (BP) of the respondents were measured, while body mass index (BMI) were calculated using standard methods. Hypertension, overweight and obesity were recorded high among participants. About 22\%, 28.8\% and 34.7\% were in the categories of prehypertension, stage by hypertension and stage 2 hypertension respectively. A total of $36.16 \%$ were overweight and $9.3 \%$ obsessed. This study demonstrated high prevalence of hypertension overweight and obesity among the adolescents in Port Harcourt other intervention to promote healthy eating habits and life styles, especially among high risk groups are suggested. Similar studies should be conducted in a rural setting.
\end{abstract}

Keywords: Consumption Pattern; BMI; Blood Pressure; Dietary Habit; Anthropometric.

Cite This Article: Wordu G. O., and Wachukwu- Chikodi H. I. (2019). "DIETARY INTAKE AND PREVALENCE OF ADOLESCENT HYPERTENSIVE IN PORT HARCOURT, NIGERIA." International Journal of Research - Granthaalayah, 7(7), 22-29. https://doi.org/10.29121/granthaalayah.v7.i7.2019.710.

\section{Introduction}

Recent global figures indicate that the prevalence of hypertension is not just a problem of the developed countries but is also on the increase in the developing world (WHO, 2013). Hypertension is the leading causes of morbidity and mortality worldwide (WHO, 2008).

Many people with hypertension are unaware of their condition and among those with hypertension, treatment is infrequent and inadequate. When selected major risk factors were assessed, the leading global risk for mortality in the world were found to be high blood pressure (which accounted for $13 \%$ of the global deaths (WHO, 2011), tobacco used (9\%) physical inactivity (6\%), overweight and obesity (5\%). These are the factors for developing chromic diseases such as heart 
diseases, diabetes mellitus and cancer (WHO, 2011). The global prevalence of hypertension has been increasing since 2000 (Berenon, 2002). It is projected to increase to 1.54 billion affected individuals and a prevalence rate of $29.4 \%$ in 2025 (Kearney, et al; 2005). Incidence rate of hypertension range from $3 \%$ to $30 \mathrm{~T}$ depending on the age, gender, ethnicity, rate and body size of population studies (WHO, 2013).

A recent community base study of rural and semi-urban population in Enugu, Nigeria, put the prevalence of hypertension in the area at 34.8\% (Wasi et al, 2011).

Uncontrolled hypertension is associated with serious organ damage including heart diseases, stroke, blindness, renal diseases (Pale, et al 2003). Major target organ complication of hypertension such as congestive heart failure, ischemic heart disease, diastolic disfunction stroke and renal failure has been established by various researchers in Nigeria. These serious complications can be prevented by adequate blood pressure control as established by (Cuspidi, et al, 2000).

Hypertension is the commest non-communicable disease affecting with children and adults (Juhasz, et al; 2010). The younger the age of onset of hypertension, the greater the reduction in life expectancy if not managed properly (M C Niece et al; 2007). The prevalence of hypertension is children is on the rise (Din-Dziethan, et al; 2007) as blood pressure increase with growth and development adolescent hypertension has been linked to obesity, diets high in fat and sodium, sedentary behaviour, insufficient physical activity and family history of hypertension and birth weight it is evident that children with elevated blood pressure tend to maintain that level of blood pressure into adulthood (Anjana, et al; 2005).

The school as a learning place for adolescents where different adolescents from different background come together to learn with different eating habits and life styles, positional to station, the prevalence and hypertension in Port Harcourt Nigeria. Adolescents therefore, represents the age bracket between childhood and adulthood hence this study is set to determine the prevalence of hypertension among adolescents in Port Harcourt.

\section{Material and Methods}

\section{Study Locations}

The study was carried out in Port Harcourt Mega-city in Rivers State of Nigeria between January and June 2018. Port Harcourt is the largest city in south-south part of Nigeria with many industrial outlay.

\section{Study Design}

The study was cross-sectional and descriptive in design.

\section{The Population of Study}

Study population and size determination of the study participants were male and female adolescents (11-19 years) in secondary schools. The secondary schools included, government secondary school, Borokiri, Enitonia secondary school and Baptist High School, Port Harcourt. 
To determine the sample size of the study, the prevalence of hypertension in south-south, Nigeria according to Ofuya, (2007) was $11 \%$ using the Cochrane formula in the calculation;

$$
n=\frac{z^{2} p q}{d^{2}}
$$

Where $\mathrm{n} \quad=\quad$ minimum sample size

$$
\begin{aligned}
& \mathrm{Z}=\quad \text { Standard normal deviation } 1.96 \text { which corresponds to } \\
& \text { 95\% confidence level. } \\
& \mathrm{P}=\text { prevalence rate, } 11.0 \%=.11 \\
& \mathrm{q}=1-\mathrm{p}=1-0.11=0.89 \\
& \mathrm{~d}=\quad \text { desired precision }=5 \%=0.05 \\
& \text { Thus: } \mathrm{n}=\frac{1.96^{2} \times 0.11 \times 0.7}{0.05^{2}}=150
\end{aligned}
$$

150 students were randomly selected from the selected secondary schools in Port Harcourt.

\section{Data Collection}

The schools were visited few weeks before the commencement of the study for feminization purpose whereby the details and importance of the study were explained to the students and teachers. The apparatus used were, standard mercury sphygmomanometer, weighting scale and meter rule were shown to the students.

\section{Anthropometric Measurements}

Heights: The height of the participants were measured without shoes to the nearest $0.1 \mathrm{~cm}$ while in an erect position against a vertical scale and with the head position and that the top of external auditory meatus was level with the inferior many in of the bony orbit (Marfell Jones, 2006).

Weight: Body weight was measured with a digital weighting scale after chocking for zero error at each measurement, and the reading was taken to the nearest $0.1 \mathrm{~kg}$. The subjects were measured barefoot, wearing light clothing and with the width distributed equally on each leg (Marfelt-Jones, 2006).

Calculation of body mass index (BMI)

The nutritional status of the subjects were assessed through body mass index (BMI). The BMI was calculated as the weight in kilograms divided by the height in meters squared $\left(\mathrm{Kg} / \mathrm{m}^{2}\right)$ and classified as underweight, normal weight overweight and obesity according to the international BMI cut off paints for adolescents (Cole, et al, 2007).

\section{Blood pressure Measurement}

Blood pressure measurement were made using sphygmomanometer (OMRON blood pressure monitor). Three measurements of systolic blood pressure (SBP) and diastolic blood pressure (DBP) measured in millimeter per mercury ( $\mathrm{mmHg}$ ) were taken. All tight cloths from the arm was removed. A cuff that inflates was wrapped round upper arm, a tube leads out to the cuff. Each measurement was taken after the participants had rested for at least 10 minutes in a sitting position 
with the arm rested on a table such that the middle of the forearm above the level of the heart. The measurements followed the recommendation of the National High Blood Pressure Education Program (NHBPEP) (NIH publication No. 05-5267, May 2005).

\section{Data Analysis}

Data was verified for accuracy and SPSS computer package version 20.0 was used for data analysis. Data was analyzed using descriptive statistical methods such as frequency and percentage. Inferential statistics such as chi-square was used to find out the relationship between variables.

\section{Results}

The study comprised mostly $(60 \%)$ me and $100 \%$ single (Tables) half of the participants $(50.0 \%)$ were of age 17-19, secondary by the age bracket of 14-16 (28.7\%).

Table 1: socio-demographic characteristics of the respondent

\begin{tabular}{|l|l|l|}
\hline Variable & Frequency & Percentage \\
\hline Sex & & \\
\hline Male & 90 & $60 \%$ \\
\hline Female & 60 & $40 \%$ \\
\hline Total & $\mathbf{1 5 0}$ & $\mathbf{1 0 0}$ \\
\hline Marital status & & \\
\hline Single & 150 & 100 \\
\hline Married & 0 & 0 \\
\hline Total & $\mathbf{1 5 0}$ & $\mathbf{1 0 0}$ \\
\hline Age & & \\
\hline $11-13$ & 32 & 21.3 \\
\hline $14-16$ & 43 & 28.7 \\
\hline 17.19 & 75 & 50.0 \\
\hline Total & $\mathbf{1 5 0}$ & $\mathbf{1 0 0}$ \\
\hline
\end{tabular}

Table 2 shows that $13.3 \%$ of the participant were underweight, while $36.0 \%$ of the adolescents were overweight and $9.3 \%$ were obese.

Table 2: MBI of the participants in the study

\begin{tabular}{lll}
\hline Variable & Frequency & Percentage \\
\hline$<18.5$ (underweight) & 20 & 13.3 \\
$18.5-24.9$ (normal weight) & 62 & 41.3 \\
$25.9-29.9$ (overweight) & 54 & 36.1 \\
30 and above (obese) & 14 & 9.3 \\
\hline
\end{tabular}

Table 3 shows the classification of blood pressure (BP) of the adolescents. About $14.7 \%$ of them were on stage 2 - hypertension while $22.0 \%$ were in stake 1 hypertension serious. Only $34.7 \%$ had normal blood pressure. 
Table 3: blood pressure profile of the respondent

\begin{tabular}{|l|l|l|}
\hline Variable & Frequency & Percentage \\
\hline$<\frac{120}{80}$ (Normal) & 82 & 34.7 \\
\hline$\frac{120}{80}-\frac{139}{89}$ (pre-hypertension) & 43 & 28.7 \\
\hline$\frac{140}{99}-\frac{159}{99}$ (stage 1 hypertension) & 33 & 22.0 \\
\hline$\geq \frac{160}{100}$ (stage 2 hypertension) & 22 & 147 \\
\hline Total & 150 & 100 \\
\hline
\end{tabular}

Table 4 presented the eating profile of the respondents. Many of them ate three times $37.3 \%$ per day, with $12.0 \%$ ate two times daily and 5.3\% skip meals. More than half of them (56.0) enjoy dinner while only $13.3 \%$ of them ate breakfast.

Table 4: Eating profile of respondents

\begin{tabular}{|l|l|l|}
\hline Variable & Frequency & Percentage \\
\hline Times of eating per day & & \\
\hline Three times & 56 & 37.3 \\
\hline Two times & 18 & 12.0 \\
\hline More than three times & 68 & 45.3 \\
\hline Skipping meals & 8 & 5.3 \\
\hline Total & 150 & 100 \\
\hline At Dinner & 84 & 56.0 \\
\hline At lunch & 10 & 6.7 \\
\hline At breakfast & 20 & 13.3 \\
\hline All of the above & 36 & 24.0 \\
\hline Total & $\mathbf{1 5 0}$ & $\mathbf{1 0 0}$ \\
\hline
\end{tabular}

Table 5 shows the life characteristics of the respondents. The result revealed that $23.3 \%$ of the respondents ate vegetables and fruit everyday while $16.7 \%$ enjoy fruits and vegetables once per week. Similarly, majority of them enjoy physical activity. Most of them (69.3\%) never drank alcoholic beverages. Majority of them $(96.0 \%)$ of the respondents don't smoke. The table also shows that majority (65.3\%) of them took high salt intake. In the same vein, the responded high consumption of fatty food (68.0\%).

Table 5: Life style characteristics of the respondents

\begin{tabular}{|l|l|l|}
\hline Variable & Frequency & Percentage \\
\hline Consumption of fruits and vegetable & & \\
\hline Once per week & 25 & 16.7 \\
\hline 2-3 days per week & 25 & 16.7 \\
\hline 4-5 days per week & 20 & 13.3 \\
\hline Every day & 35 & 23.3 \\
\hline More for week & 45 & 30.0 \\
\hline
\end{tabular}




\begin{tabular}{|l|l|l|}
\hline Total & 150 & 100 \\
\hline Salt intake & 98 & 65.3 \\
\hline High & 12 & 8.0 \\
\hline Moderate & 40 & 26.7 \\
\hline Total & 150 & 100 \\
\hline Smoking & & \\
\hline Smokers & 6 & 4.0 \\
\hline Non smoke & 144 & 96.0 \\
\hline Total & 150 & 100 \\
\hline Drinking Alcohol & & \\
\hline Yes & 46 & 30.7 \\
\hline No & 104 & 69.3 \\
\hline Physical activities & 150 & 100 \\
\hline Yes & 110 & 73.4 \\
\hline No & 40 & 26.6 \\
\hline Total & 150 & 100 \\
\hline Consumption of fatty food & & \\
\hline Always & 102 & 68.0 \\
\hline Sometimes & 18 & 12.0 \\
\hline Rarely & 30 & 20.0 \\
\hline Total & $\mathbf{1 5 0}$ & $\mathbf{1 0 0}$ \\
\hline
\end{tabular}

\section{Discussion}

This study recorded high prevalence of hypertension, overweight and obesity among adolescents in Port Harcourt. The causes of obesity and hypertension among the participants are not forfetched as these groups of people are mostly engaged in eating fatty foods and high salt intake as was found by Atolabi, et al, 2004.

Epidemiological reports have shown that increase in BMI and body fat facilitate early development of atherosclerosis in children and adolescents which may predispose the adolescent individual to higher blood pressure and subsequently hypertension (Bierensons 2002). The prevalence of hypertension in children and adolescents seems to be increasing (Sarof, et al, 2004). This rise is partially because of the increasing prevalence of obesity among children and adolescents, especially those that reside in big cities. There is evidence that hypertension is children and adolescents can lead to adult hypertension (Kiesdling et, al; 2008). Presence of hypertension in children and adolescents may contribute to the early development of coronary artery disease.

The study on Ondo town in Ondo state, Nigeria, also revealed elevated BP among the adolescents. This finding agreed with other epidemiological studies in Nigeria (Bugaje et al, 2005; Asani and Bode-Thomas, 2005; Ujunwa, et al; 2013), and other developing countires (Chiolero, et al, 2007; Mahyar, et al 2009). High blood pressure was once considered to be a rare condition in children (Chiolero, et al, 2013), it has become clear that elevated blood pressure (BP) is a life course problem that can become evident in adolescent and can be progressive throughout childhood into adulthood (Clean and Wang, 2008). There has been evidence that children with elevated blood 
pressure have an increased risk of end-organ damage, such as ventricular hypertrophy and increased carotid thickness (Waseem, 2011).

Based on reports obtained in this study, alcoholism, high salt intake, and high fat intake were common among the participants. This agrees with American Heart Federation (AHF), which stated that dietary salt intake is a significant factor in raising blood pressure. Thus moderate salt intake is recommended as a positive step for maintaining a healthy diet.

\section{Conclusion}

The present study revealed high prevalence of overweight, obesity and hypertension, which may be a predictive of high incidence of cardiovascular diseases in the very near future. Therefore, urgent intervention strategies to prevent and control hypertension among adolescents are needed. This may include screening for susceptible adolescent and implementation of health programmes to address the underlying causes. similar studies should be carried out in rural settings in Rivers State, Nigeria.

\section{References}

[1] WHO, (2013). Obesity and overweight. WHO fact sheet. World Health organization, Genera, Switzerland.

[2] WHO (2008). Global brief on hypertension. World Health Day. World Health Organisation, Geneva, Switzerland.

[3] WHO (2011). Global status report on non-communicable diseases in 2010. World Health Organization Geneva, Switzerland.

[4] Berenson, G. S. (2002). Childhood risk factors predict adult risk associated with among school children in Aligerh, Indian Journal of Public Health 55:121-124.

[5] Kearney, P. M; Whelton, M; Rayonolds, K; Muntner, P; Whilton, P. and Hej (2006). Global Burden of hypertension anslysis of worldwide data. Lancert, 365: No 9455, pp. 217-223.

[6] Wasi, I. I Ijioma, C. K. Onwubere, B. C. Arodiwe, E. Onoduqo, O. and Okafor, C. (2011) High Prevalence and Low awareness of Hypertension in a market population in Enugu, Nigeria. International Journal of Hypertension: 8695.

[7] Pate, R. R. Stevens, J; Webber, L. S., Dowda, M; Murray, D. M; Young, D. R. and Going, S. (2009). Age 0 related change in physical activity in adolescent girls. Journal of Adolescent Health, 44(3): $275-82$.

[8] Cuspidi, C; Lonatil, L; Samperi, L; Michev, L; Macca, G; Rocanova, J. I. Salerno, M; Fusi, G. Leonelti, G and Zanchelti, A (2000). Prevalence of target organ damage in treated hypertensive patients: different impact of clinic and ambulatory blood pressure control. Journal of hypertensioin 18:083-809.

[9] Juhasz, M; Katona, E; Settakis, G; Paragh, G; Molnar, C. Fulesdi, B and Pall, D (2010) Gender related differences in adolescent hypertension and intarget organ effects Journal of Women Health 19:759-765.

[10] MC Niece, K. L. Poffenbarger, T. S. Turner, J. L; Franco; K. D. Sorof, J, M and Portman, R. J. (2007). Prevalence of hypertension and pre-hypertension among adolescents. Journal of paediatrics, 150(6): 640-644.

[11] Din-Dziethan, R; Liu, Y; Bielo, M. V. and Shamsa, F. (2007). High Blood pressure trends in children and adolescents in national surveys. 1963 to 2000. Circulation 116: 1488-1496.

[12] Anjana, P; Kaur, N., Kumari, K and sihut S. (2005). Variation in blood pressure among school children of Amritsar (Punjab) Anthropolgist, 7:201-204. 
[13] Ofuya, Z. M. (2007). The incidence of hypertension among a select population of adults in the Niger Delta Region of Nigeria. Southeast Asian Journal of Tropic Medicine public Health, 38(5): 947-949.

[14] Marfell - Jones, M (2006). International standards for antorpometric assessment. International society for the advanpotchef streocement of kinanthropometry, south African: Potchef stroom.

[15] Cole, T. J. Flegal, K.M., Nicholls, Dand Jackson, A. A. (2007). Body mass index cut offs to define thinness in children and adolescents international survey British Medical Journal, 335:194.

[16] Afolabi, W. A. Addo, A. A. and Sonibare, M. A. (2004) Activity pattern of energy intake and obesity among Nigeria urban market women. International Journal of Food Science and Nutrition 55(2):85-90.

[17] Berenson, G. S. (2002). Childhood risk factors predict adult risk associated with subclinical cardiovascular disease. The Bogalusa heart study. America Journal of cardiology 90:3-7.

[18] Sarof, J. M; Lai, D., Turner, J; Pfoffenbarger, T and Portman, R. J. (2004) Overweight, ethnicity and prevalence of hypertension in school age children. Paediatrics, 113:475-82.

[19] Kiessling, S. G; McClanahaml K. K. and Omer, H,. A, (2008). Obesity hypertension and mental health evaluation in adolescents. A comprehensive approach international journal of adolescent medicine and health, 20:5-15.

[20] Bugaje, M.A. Yakubu, A. M. and Ogala, W. N. (2005) prevalence of adolescent hypertension in zaria. Nigeria Journal of paediatrics, 32:77-82.

[21] Asani, M. O. and Bode - Thomas, F. (2005) Blood Pressure pattern and its correlates among primary school children in Jos, Nigeria. Highland medial research 3:29-35.

[22] Ujunwa, F. A., Ikefuna, A. N; Nwokoka, A, R, and chinawa, J, W. (2013). Hypertension among adolescent in Secondary schools in Enugu South East, Nigeria. Italian Journal of Pediatrics, 39:70.

[23] Choleo, A. Bouet, P. and Paradiz, G. (2013) Screening for elevated blood pressure in children and adolescents. A criteria appraisal. Journal of America medical association Paediatrics, 167:26673.

[24] Mahyar, A. Eberahemi M; Shahsavar, and Rahmani, Y (2009). Blood pressure of primary - school children of Eqhbalism city, Islamic Republic of Iran East Mediterranean Health Journal, 15:144954.

[25] Chen, $X$ and Wang, Y. (2008). Tracking of blood pressure from children to adulthood: a systematic review and metaregresion analysis. Circulation, 117:3171-3180.

[26] Durrani, A. M., and Waseem, F. (2011) Blood pressure distribution and its relation to authropometric measurements among school children in Aligarth. Indian Journal of Public Health $55: 121-124$.

\footnotetext{
*Corresponding author.

E-mail address: wordugab@yahoo.com
} 